\title{
Neoplastic disorders in 100 patients with adult celiac disease
}

\author{
HUGH J FREEMAN MD
}

HJ FreEmAN. Neoplastic disorders in 100 patients with adult celiac disease. Can J Gastroenterol 1996;10(3):163-166. Previous reports have suggested that the incidence of some neoplastic disorders, particularly malignant lymphoma, is increased in patients with celiac disease. In this study, the type and number of neoplastic disorders detected in 100 consecutive celiac disease patients were explored. Sixty-five patients were initially diagnosed with celiac disease before, and 35 after, age 60 years. Ten elderly celiac patients had lymphoma or small intestinal adenocarcinoma. Although the overall incidence of malignant lymphoma was $8 \%$, similar to that in other centres, the incidence in elderly celiac patients was $23 \%$ in this study. Celiac disease was detected before or after the diagnosis of lymphoma or small intestinal adenocarcinoma. In some patients, epithelial lymphocytosis was evident in the gastric, colonic or biliary tract epithelium. In addition, other immune-mediated disorders, dermatitis herpetiformis and autoimmune thyroiditis, were common. Finally, other malignant disorders of the esophagus, stomach and colon were not detected.

Key Words: Celiac disease, Colon cancer, Dermatitis herpetiformis, Hypothyroidism, Lymphoma, Small bowel carcinoma

\section{Maladies néoplasiques chez 100 patients atteints d'une maladie coliaque de l'adulte}

RÉSUMÉ : Selon des rapports antérieurs, l'incidence de certaines maladies néoplasiques, particulièrement celle des lymphomes malins, est plus grande chez les patients souffrant de maladie cœliaque. Dans cette étude, le type et le nombre de maladies néoplasiques décelées chez 100 patients consécutifs souffrant de maladie cœliaque ont été examinés. Soixante-cinq patients ont d'abord reçu le diagnostic de maladie coliaque avant l'âge de 60 ans et 35 après. Dix patients âgés atteints de maladie cœliaque présentaient un lymphome ou un adénocarcinome de l'intestin grêle. Si l'incidence globale de lymphomes malins était de $8 \%$, soit semblable à celle d'autres centres, leur incidence chez les patients âgés atteints de maladie cœliaque était de $23 \%$ dans cette étude. La maladie cœliaque a été décelée avant ou après le diagnostic de lymphome ou celui de l'adénocarcinome de l'intestin grêle. Chez certains patients, une lymphocytose épithéliale était présente dans l'épithélium gastrique, colique ou des voies biliaires. De plus, d'autres troubles à médiation immunitaire, comme la dermatite herpétiforme et la thyroïdite auto-immune étaient fréquents. Finalement, aucune autre affection maligne de l'œsophage, de l'estomac et du côlon n'ont ou être dépistées.

$I_{\text {de }}^{\text {n }}$ $\mathrm{n}$ adults with celiac disease, malignant complications may develop, especially in the small intestine. In long term follow-up studies of patients with celiac disease, particularly from Birmingham, England (1,2), an increased incidence of malignant lymphoma - especially in the small intestine has been demonstrated. In addition, patients with abdominal lymphoma may have clinically occult celiac disease (3). Finally, an increased incidence of other neoplastic disorders may be seen, including small intestinal adenocarcinoma $(4,5)$.

Recently there has been increased recognition of celiac disease in the elderly, with initial diagnosis often established after age 60 years $(6,7)$. In those patients, the diagnosis was based on small intestinal biopsies characteristic of celiac disease as well as a response to a gluten-free diet. This unusual experience has provided an important opportunity to examine the types, sites and frequencies of malignant disease in this elderly celiac patient population.

The results indicate that adult celiac disease patients have

Presented in part at the American Gastroenterology Association Annual Meeting held May 1995 in San Diego, California, USA

Department of Medicine (Gastroenterology), University of British Columbia, Vancouver, British Columbia

Correspondence and reprints: Dr Hugh Freeman, ACU F-137, Vancouver Hospital (UBC Site), 2211 Wesbrook Mall, Vancouver, British

Columbia V6T 1W5. Telephone 604-822-7216, fax 604-822-7236

Received for publication April 4, 1995. Accepted August 22, 1995 
TABLE 1

Malignancy in celiacs*

\begin{tabular}{lc}
\hline Malignancy & Number (\%) \\
\hline Lymphoma of small bowel & $6(18 \%)$ \\
Extra-intestinal nodal lymphoma & $4(12 \%)^{\dagger}$ \\
Small bowel adenocarcinoma & $2(6 \%)$ \\
Gynecological malignancy (ovarian) & $2(6 \%)$ \\
Breast carcinoma & $1(3 \%)$ \\
Colonic adenoma & $1(3 \%)$ \\
Thyroid adenoma & $1(3 \%)$ \\
Skin cancer & $2(6 \%)$ \\
${ }^{*} n=35$ elderly celiacs diagnosed after age 60 years; in some, more than one \\
type of malignancy occurred; ${ }^{+}$Sites include tonsillar, inguinal and cervical \\
nodes
\end{tabular}

an increased rate of malignant lymphoma, especially in the small intestine, and that detection of celiac disease may occur before or after the diagnosis of lymphoma. Epithelial lymphocytosis is often evident in these celiac disease patients - particularly in gastric, colonic and/or biliary tract mucosa - and other immune-mediated disorders may be present, including dermatitis herpetiformis and thyroiditis. Finally, common malignant neoplastic epithelial lesions often found in other gastrointestinal sites, such as the esophagus, stomach and colorectum, were not detected in adult celiac disease patients.

\section{PATIENTS AND METHODS}

From January 1982 to December 1994 inclusive, 100 patients with adult celiac disease were followed; 35 were initially diagnosed during or after their seventh decade at the University of British Columbia Hospital, Vancouver, British Columbia. All except four of these 35 patients have been followed and reviewed on an annual basis in an adult celiac disease clinic, first established in 1982. One of the four patients died of pneumonia six months after the initial diagnosis while two others died of metastatic ovarian and breast carcinoma four and nine months after the initial diagnosis of celiac disease, respectively. The fourth patient died about one month after celiac disease was diagnosed with progressive liver failure. Four other patients, each followed for over one year, died of lymphoma during the past 13 years, including two patients previously reported elsewhere $(8,9)$. One other patient, recently reported (10), died of an extensive duodenal adenocarcinoma, while another died of metastatic ovarian carcinoma about 16 months after diagnosis of celiac disease.

Office and hospital records of all patients were reviewed. Details of clinical presentation and past medical history were recorded as well as hematological (hemoglobin, white blood cell count, platelet count, peripheral blood smear) and biochemical results (carotene, iron and iron binding capacity, folic acid, vitamin B12, calcium, phosphate, total protein, albumin, prothrombin time, immunoglobulin quantitation, amylase, and thyroid and liver chemistry tests). After biopsies of the small intestine were done, patients were reviewed by a clinical dietitian with a special interest in celiac disease who provided specific instructions on the gluten-free diet. Patients were reviewed periodically as required to address any concerns regarding diet treatment.
Compliance and response to a prescribed strict gluten-free diet were assessed during each clinic visit.

Each of the 35 patients had a severely abnormal 'flat' small intestinal biopsy (so-called crypt hyperplastic villous atrophy) obtained before institution of a gluten-free diet (7). In 34 patients, initial biopsies were severely abnormal and treatment was initiated within two weeks. In one patient with small bowel lymphoma, reported elsewhere (8), multiple small intestinal biopsies on a high gluten diet were required to demonstrate the typical histological features of adult celiac disease. Biopsies from at least two separate sites in the small intestine in each patient were obtained with at least one biopsy from a site distal to the descending duodenum. Biopsies were also obtained from the gastric mucosa, usually the anatomical prepyloric gastric antrum, lesser curvature. Finally, at least one colorectal biopsy was obtained from all patients, usually from a valve in the distal $25 \mathrm{~cm}$, using either a fibreoptic flexible sigmoidoscope or colonoscope. In 34 patients, biopsies of the small intestine were repeated after at least eight weeks to determine whether a histological response to a gluten-free diet had occurred. In one patient with a small bowel adenocarcinoma (10), biopsies were repeated after hospitalization for six weeks on a gluten-free diet in a clinical investigation unit setting to ensure compliance.

For diagnosis of lymphoma, surgically resected specimens or biopsy material from the small intestine or lymph nodes were used. In four of five patients with lymphoma or small intestinal adenocarcinoma who died, additional histological materials were obtained from autopsies.

\section{RESULTS}

Types and frequencies of neoplastic complications: The types and frequencies of neoplastic disorders in the 35 elderly celiac disease patients initially diagnosed after age 60 years are listed in Table 1. No malignant neoplasms have been detected in the 65 adult celiac disease patients initially diagnosed before age 60 years. Ten of the 35 patients (almost $30 \%$ ) with adult celiac disease initially diagnosed after age 60 years had a lymphoma or a small intestinal adenocarcinoma. Five of these patients died, four with lymphomas and one with a small bowel adenocarcinoma; all were in their eighth or ninth decade. Three other patients with adult celiac disease diagnosed after age 60 years had malignant disorders; two had metastatic ovarian carcinoma and one had metastatic breast carcinoma. All of these patients died within two years of diagnosis of the malignant disorder. Although a single colon adenoma was detected, invasive epithelial malignant disease was not detected in any other gastrointestinal site, including the esophagus, stomach or colorectum.

Small intestinal and/or nodal lymphoma: Six of the eight patients with a lymphoma in this group of 35 elderly adult celiacs (ie, $23 \%$ of elderly celiac disease patients or $8 \%$ of the 100 adult celiac disease patients from this single hospital) had small intestinal involvement, including two with nodal disease in extra-abdominal sites (tonsillar and retroperitoneal nodes). Two lymphoma patients had nodal involvement only 
(inguinal and cervical nodes) without small intestinal lymphoma. In four patients, lymphoma was confined to the small intestine (in at least one site). In one patient, multifocal small intestinal involvement was present (8). As shown in Table 2, any site within the small intestine can be involved; in this group of eight patients with lymphoma, however, lymphoma was most commonly detected in the jejunum.

Associated gastrointestinal findings: Common clinical disorders associated with adult celiac disease are shown in Table 2. These included epithelial lymphocytosis as lymphocytic gastritis (11) in three patients, lymphocytic colitis (12) in two patients and lymphocytic sclerosing cholangitis (13) in one patient. In addition, cavitated mesenteric lymph nodes associated with splenic hypofunction were detected in two patients with lymphoma who died; one was previously reported in detail elsewhere as the first case of mesenteric lymph node cavitation syndrome and hyposplenism complicated by lymphoma (9).

Associated nongastrointestinal findings: In this series of 10 patients with lymphoma or small bowel adenocarcinoma, dermatitis herpetiformis was reported in four patients (40\%), and confirms observations from a previous study from a different hospital of seven patients with lymphoma and clinically occult celiac disease, some with dermatitis herpetiformis (3). In addition, a high frequency of thyroid disease was detected (14). Four of 10 patients (40\%) with either lymphoma or small bowel adenocarcinoma had hypothyroidism (based on low serum thyroxine, elevated thyroid-stimulating hormone or both) accompanied by positive thyroid antibodies most typical of thyroiditis. Interestingly, three of the four patients shared common clinicopathological features of dermatitis herpetiformis, thyroiditis, hypothyroidism, epithelial lymphocytosis (gastric, colonic and/or biliary tract) and celiac disease. While this relationship has not been previously described, it may reflect, in part, the observation (15) that the incidence of thyroid disease, particularly hypothyroidism associated with increased titres of thyroid antibodies, increases with advancing age. Alternatively, this may represent a distinct clinical and pathological subset of patients with celiac disease who have an associated multisystem syndrome characterized by increased numbers of intraepithelial lymphocytes at other sites in the gastrointestinal tract as well as skin and thyroid epithelium.

Other gastrointestinal neoplasms: The absence of other neoplastic disorders in the gastrointestinal tract in this elderly population was an unexpected finding. Moreover, only two patients had preneoplastic epithelial disorders: one had a colonic adenoma and one had a Barrett's esophagus. The detection of a single colonic adenoma in an elderly population with a late diagnosis of celiac disease has special significance because the patients in the present study had, as a minimum, a limited endoscopic examination of the distal colon (ie, flexible sigmoidoscopy) and colorectal biopsy. Similarly, the failure to observe Barrett's type mucosa during upper endoscopic studies was surprising because the latter may be expected to occur more frequently in a patient population
TABLE 2

Celiac patients with lymphoma or small bowel carcinoma

\begin{tabular}{|c|c|c|}
\hline Age*/sex & Lymphoma site(s) & Other associated findings \\
\hline $70 / \mathrm{male}^{\dagger}$ & $\begin{array}{c}\text { Duodenum and } \\
\text { jejunum } \\
\end{array}$ & $\begin{array}{l}\text { Mesenteric lymph node cavitation } \\
\text { with hyposplenism, ectopic } \\
\text { gastric mucosa, lymphocytic } \\
\text { gastritis, hypothyroidism, der- } \\
\text { matitis herpetiformis (9) }\end{array}$ \\
\hline $60 /$ male & Inguinal node & $\begin{array}{l}\text { Lymphocytic colitis, lymphocytic } \\
\text { sclerosing cholangitis, hypo- } \\
\text { thyroidism, dermatitis herpeti- } \\
\text { formis (13) }\end{array}$ \\
\hline $84 /$ male & Duodenum ${ }^{\ddagger}$ & Hypothyroidism \\
\hline 62/female & Jejunum & Dermatitis herpetiformis \\
\hline $74 /$ female $^{\dagger}$ & $\begin{array}{l}\text { Jejunum and il- } \\
\text { eum }^{\ddagger}\end{array}$ & $\begin{array}{l}\text { Mesenteric lymph node cavitation } \\
\text { and hyposplenism, lympho- } \\
\text { cytic gastritis, vasculitis }\end{array}$ \\
\hline $73 /$ female $^{\dagger}$ & $\begin{array}{l}\text { Tonsil and jeju- } \\
\text { num }(8)^{\ddagger}\end{array}$ & \\
\hline $81 /$ female & Cervical node & \\
\hline $74 /$ male $^{\dagger}$ & $\begin{array}{l}\text { Retroperitoneal } \\
\text { node and jeju- } \\
\text { num }\end{array}$ & \\
\hline \multicolumn{3}{|c|}{ Small bowel adenocarcinoma } \\
\hline $60 /$ male & $\begin{array}{l}\text { Jejunum and il- } \\
\text { eum }^{\ddagger}\end{array}$ & $\begin{array}{l}\text { Lymphocytic colitis, hypo- thyroid- } \\
\text { ism, dermatitis herpetiformis }\end{array}$ \\
\hline $89 / \mathrm{male}^{\dagger}$ & Duodenum & $\begin{array}{l}\text { Lymphocytic gastritis, Barrett's } \\
\text { esophagus (10) }\end{array}$ \\
\hline
\end{tabular}

${ }^{*}$ Age at diagnosis of celiac disease; ${ }^{\dagger}$ Deceased; ${ }^{\ddagger}$ Diagnosed after celiac disease detected

reported elsewhere to have an increased risk of esophageal cancer (4).

\section{DISCUSSION}

This study explored the frequencies of different types of malignant disorders detected in a population of 100 celiac disease patients seen consecutively at a single teaching hospital. Diagnosis of celiac disease was based on characteristic histological features and response to a gluten-free diet. The overall incidence of lymphoma in the present report was $8 \%$, comparable with observations in several other large series of celiac disease patients (16-21). However, this increased risk was due entirely, at least in the author's experience, to the fact that patients with celiac disease were diagnosed after age 60 years. In the 35 elderly celiac patients, the incidence of lymphoma was $23 \%$; if patients with small intestinal adenocarcinoma were also included, almost $30 \%$ of patients with celiac disease initially diagnosed after age 60 were affected by one of these two malignancies. To date, patients diagnosed with celiac disease before age 60 years have not developed a malignant complication. This suggests that the risk of lymphoma development may be more substantial if the diagnosis is initially made later in life, possibly because of continued consumption of gluten-containing foods until diagnosis of celiac disease and institution of a gluten-free diet. This observation provides additional indirect evidence that treatment with a strict gluten-free diet with resultant normalization of the small intestinal mucosa in patients with celiac disease may be critical for prevention of lymphoma and, pos- 
sibly, other small intestinal disorders such as adenocarcinoma.

Lymphomas in the celiac disease patients studied in the present report were usually located in the small intestine; in some patients, diagnosis of celiac disease was established before subsequent development of lymphoma, while in others the celiac disease was clinically occult and was diagnosed following presentation with lymphoma. These findings confirm observations from other centres, including a previous report from another Canadian teaching hospital (3). In addition, the present study confirms previous reports that have described detection of celiac disease in patients with a previously diagnosed extra-intestinal site of lymphoma $(22,23)$.

Two patients reported here had a nodal lymphoma diagnosed without evidence of small intestinal lymphoma. The first was an 81-year-old female in whom lymphoma was diagnosed in 1991 after removal of a cervical node. In 1993 she developed weight loss, and celiac disease was diagnosed. After treatment with a gluten-free diet she regained the weight. In 1995 she remained well with no evidence of recurrent lymphoma. The second patient was a 60-year-old male with long-standing dermatitis herpetiformis in whom a localized lymphoma was detected in an enlarged right inguinal lymph node in 1976 . He was treated with chemotherapy and radiation; no recurrent lymphoma was observed. In 1992 lymphocytic sclerosing cholangitis (13) and celiac disease were detected. Others in this series had nodal involvement, but in these patients there was an associated small intestinal lymphoma. In lymphoma patients with chronic diarrhea or weight loss, recurrent lymphoma or the effects of lymphoma treatment may be considered. Because of nutritional impli-

\section{REFERENCES}

1. Harris OD, Cooke WT, Thompson H, Waterhouse JAH. Malignancy in adult celiac disease and idiopathic steatorrhea. Am J Med 1967;42:899-912.

2. Cooper BT, Holmes GKT, Ferguson R, Cooke WT. Celiac disease and malignancy. Medicine 1980;59:249-61.

3. Freeman HJ, Weinstein WM, Shnitka TK, Piercey JRA, Wensel RH. Primary abdominal lymphoma. Presenting manifestation of celiac sprue or complicating dermatitis herpetiformis. Am J Med 1977;63:585-94.

4. Swinson CM, Slavin G, Coles EC, Booth CC. Coeliac disease and malignancy. Lancet 1983;i:112-7.

5. Cooke WT, Holmes GKT. Malignancy. In: Cooke WT, Holmes GKT, eds. Coeliac Disease. Edinburgh: Churchill Livingstone, 1984:172-96.

6. Hankey GL, Holmes GKT. Coeliac disease in the elderly. Gut 1994;35:65-7.

7. Freeman HJ. Clinical spectrum of biopsy-defined celiac disease in the elderly. A study of 30 patients initially diagnosed after the age of 60 . Can J Gastroenterol 1995;9:42-6.

8. Freeman HJ, Chiu BK. Multifocal small bowel lymphoma and latent celiac sprue. Gastroenterology 1986;90:1992-7.

9. Freeman HJ, Chiu BK. Small bowel malignant lymphoma complicating celiac sprue and the mesenteric lymph node cavitation syndrome. Gastroenterology 1986;90:2008-12.

10. Freeman HJ. Occult celiac disease in an octogenarian presenting with a small intestinal adenocarcinoma. Can J Gastroenterol 1994;8:354-7.

11. Wolber R, Owen D, DelBuono L, Appleman H, Freeman HJ. Lymphocytic gastritis in patients with celiac sprue and sprue-like intestinal disease. Gastroenterology 1990;98:310-5.

12. Wolber R, Owen D, Freeman HJ. Colonic lymphocytosis in patients with celiac sprue. Hum Pathol 1990;21:1092-6.

13. Freeman HJ, Kwan WC. Occult celiac disease associated with lymphocytic sclerosing cholangitis. Can J Gastroenterol 1994;8:249-52.

14. Freeman HJ. Celiac associated autoimmune thyroid disease. A study of 16 patients with overt hypothyroidism. Can J Gastroenterol 1995;9:242-6. cations, however, concomitant clinically occult celiac disease also requires exclusion.

Especially intriguing was the remarkable absence of malignant disease elsewhere in the gastrointestinal tract in these 35 elderly celiac patients (and in the entire series of 100 adult celiac disease patients). Except for a single patient with the hypothesized preneoplastic esophageal lesion (ie, Barrett's mucosa), esophageal carcinoma was not detected despite complete upper endoscopic examinations. This finding differs from observations reported from other centres, particularly the United Kingdom, suggesting that pharyngeal and esophageal carcinomas are common in celiac disease patients $(4,5,16)$. This may reflect exposure to different environmental factors in Canada compared with other countries. In addition, only one patient in this study had a colonic adenoma detected; no colonic cancer has been detected in any of the other celiac disease patients in this series. This seems to be consistent with the reported, but underemphasized, clinical experience from other centres (5,24-26).

A much higher incidence of both benign and malignant colonic neoplastic lesions (as well as breast carcinoma) should have been detected, particularly in the elderly patients. Perhaps untreated celiac disease is protective; dietary fat or fat soluble agents, including hydrocarbons or other putative cocarcinogens, that have been implicated in the pathogenesis of both colonic and breast carcinoma may be poorly absorbed and rapidly excreted. Alternatively, the immunological alterations (eg, epithelial lymphocytosis) in celiac disease may protect these patients from malignant diseases at other gastrointestinal sites. Additional studies are needed to elucidate further this observation in celiac disease patients.

15. Runnels BL, Garry PJ, Hunt WC, Standefer JC. Thyroid function in a healthy elderly population: implications for clinical evaluation. J Gerontol 1991;46:B39-44.

16. Holmes GKT, Stokes PL, Sorahan TM, Prior P, Waterhouse JAH, Cooke WT. Coeliac disease, gluten-free diet and malignancy. Gut 1976;17:612-9.

17. Selby WS, Gallagher ND. Malignancy in a 19-year experience of adult coeliac disease. Dig Dis Sci 1979;24:684-8.

18. Brandt L, Hagander B, Norden A, Stenstam M. Lymphoma of the small intestine in adult coeliac disease. Acta Med Scand 1978;204:467-70.

19. Neilson $\mathrm{OH}$, Jacobsen O, Pedersen ER, et al. Non-tropical sprue. Malignant disease and mortality rate. Scand J Gastroenterol 1985;20:13-8.

20. Logan RFA, Rifkind EA, Turner ID, Ferguson A. Mortality in coeliac disease. Gastroenterology 1989;97:265-71.

21. O'Driscoll BRC, Stevens FM, O'Gorman TA, et al. HLA type of patients with coeliac disease and malignancy in the West of Ireland. Gut 1982;23:662-5.

22. Shiboski CH, Greenspan D, Dodd CL, Daniels TE. Oral T-cell lymphoma associated with celiac sprue. Oral Surg Oral Med Oral Pathol 1993;76:54-8.

23. Doyle GJ, Rose JDG, Kesteven PJL. Pleural lymphoma in a patient presenting with malabsorption: an illustration of the clinico-pathological behavior in a case of enteropathy associated T cell lymphoma. Gut 1993;34:1463-6.

24. Howdle PD. Is coeliac disease a pre-malignant condition? In: Feighery C, O'Farrelly C, eds. Gastrointestinal Immunology and Gluten- sensitive Disease. Proceedings of the 6th International Symposium on Coeliac Disease, Trinity College, Dublin. Dublin: Oak Tree Press, 1994:181-90.

25. Askenazi A, Baratz M. Malignancy complicating celiac disease. In: Branski D, Rozen P, Kagnoff MF, eds. Gluten-sensitive Enteropathy. Basel: S Kargar, 1992:184-93.

26. Marsch S, Heer M, Sulser H, Hany A. Risk of malignancies in celiac disease - a retrospective study. Schweiz Rundsch Med Prax 1990;79:533-6. 


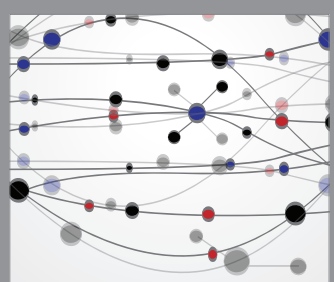

The Scientific World Journal
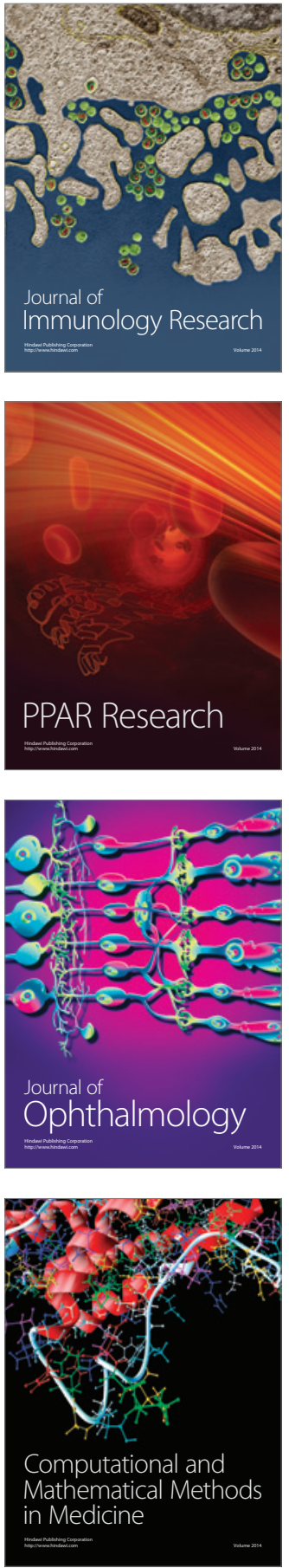

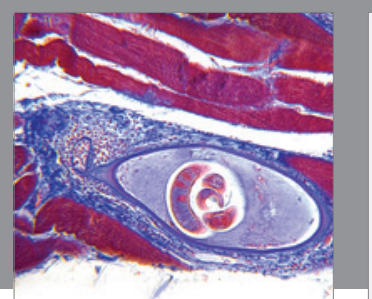

Gastroenterology Research and Practice

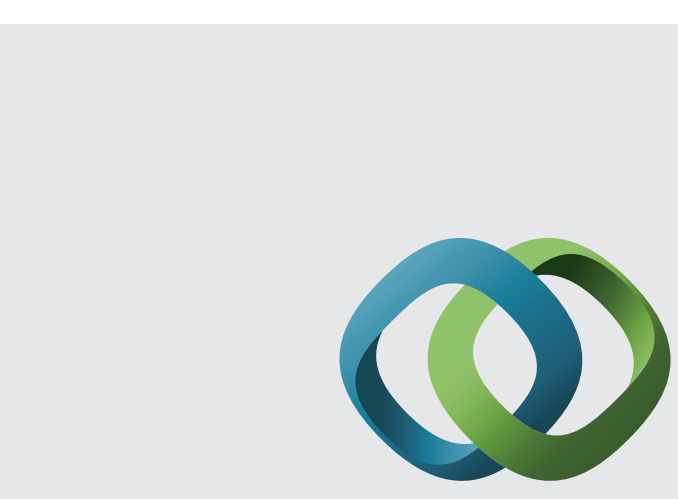

\section{Hindawi}

Submit your manuscripts at

http://www.hindawi.com
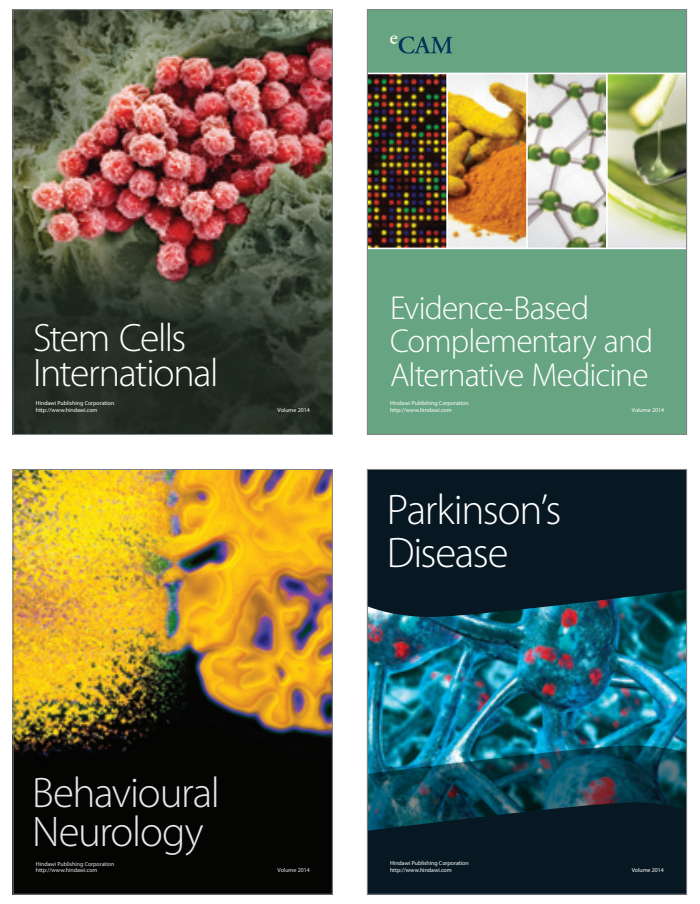
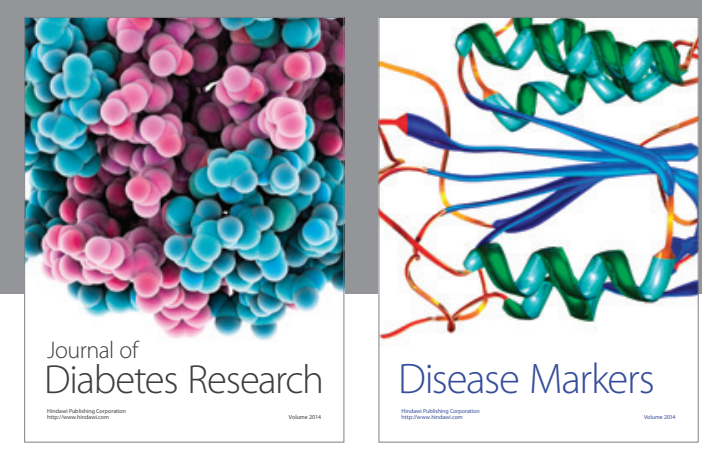

Disease Markers
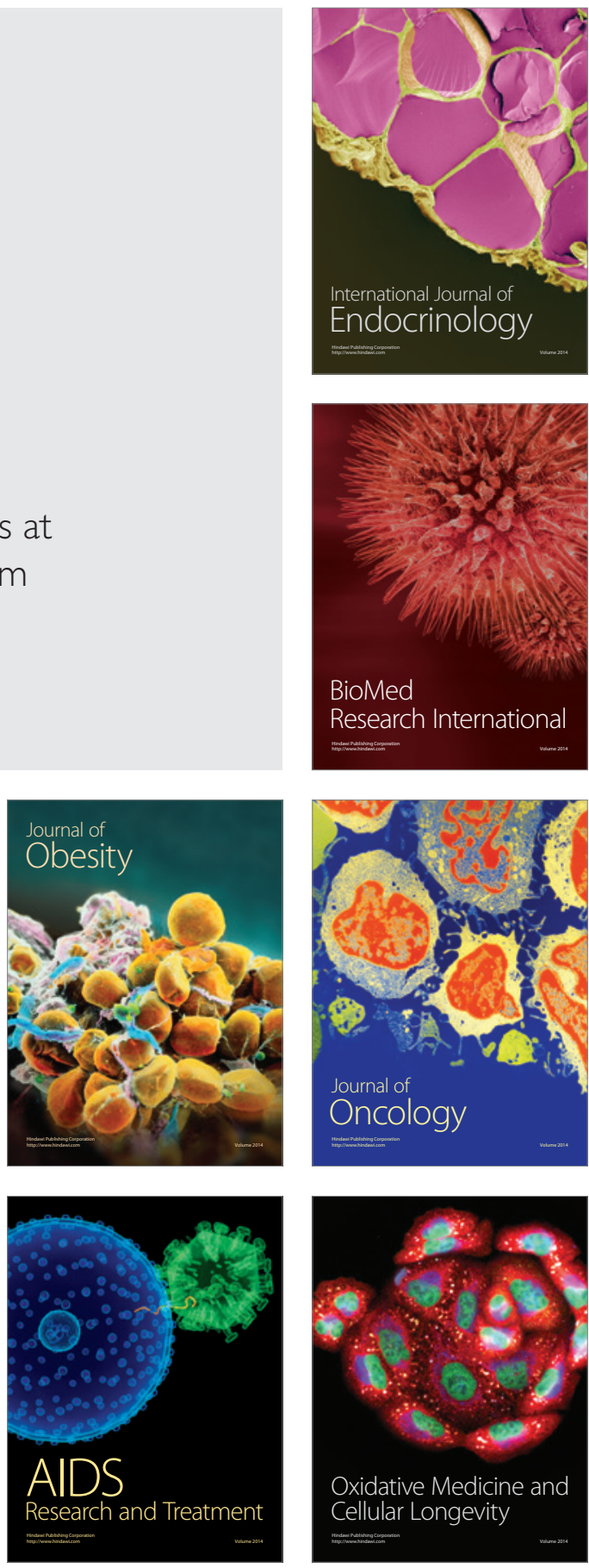